\title{
A PROPOSTA DE DESENVOLMENTO DE GESTÃO DA MANUTENÇÃO INDUSTRIAL NA BUSCA DA EXCELÊNCIA OU CLASSE MUNDIAL
}

\section{THE PROPOSAL OF THE INDUSTRIAL MAINTENANCE MANAGEMENT DEVELOPMENT IN THE SEARCH OF THE EXCELLENCE OR WORLD CLASS}

\author{
Mario Otani ${ }^{1}$; Waltair Vieira Machado ${ }^{2}$ \\ ${ }^{1}$ Federal University of Amazonas - UFAM - Manaus - Brasil mariootani@gmail.com \\ ${ }^{2}$ Federal University of Amazonas - UFAM - Manaus - Brasil waltairmachado@ufam.edu.br
}

\begin{abstract}
Resumo
O presente artigo busca uma abordagem sobre a proposta de desenvolvimento de gestão da manutenção industrial na busca da excelência ou classe mundial, recomendada as organizações que já estejam na fase controladora e, que pretendam o enfrentamento da nova fase desafiadorainovação. $O$ objetivo deste artigo é investigar e apresentar os conhecimentos em gestão da manutenção já publicados em artigos periódicos, dissertações, revistas, livros e relatórios técnicos, resumindo-se as práticas já publicadas. Constituiu-se em um trabalho de levantamento bibliográfico, pesquisa, observação, análise, classificação e interpretação dos fatos coletados e um estudo de caso - pesquisa sobre tipos de manutenções aplicadas no PIM - Pólo Industrial de Manaus. No intuito de descreverem um caso de integração de informações, critérios e práticas, unificando do modo abrangente possível das informações técnicas e de modo a criar uma consistência maior na prática da gestão da manutenção. Suporta-se a hipótese de que pela aplicação da manutenção preditiva de maneira eficiente nos setores da produção, complementadas pela manutenção detectiva e da engenharia de manutenção, as empresas caminharão para alcances dos seus objetivos estratégicos e, estar assim, melhor preparadas para lidar com os constantes desafios de um mercado competitivo e importante avanço na busca da excelência.
\end{abstract}

Palavras-chave: Manutenção Preditiva, Manutenção Detectiva, Engenharia da Manutenção e Gestão da Manutenção.

\section{Introdução}

$\mathrm{Na}$ economia globalizada dos dias de hoje, a sobrevivência das organizações depende de sua habilidade e rapidez de inovar e efetuar melhorias contínuas. Como resultado, as organizações vêm buscando incessantemente novas ferramentas de gerenciamento, que as direcionem para uma maior competitividade através da qualidade e produtividade de seus produtos, processos e serviços (KARDEC, 2004). E para o mesmo autor, atualmente a necessidade de agilidade imposta às organizações demanda cada vez mais eficácia na tomada de decisões por parte destas, e tem levado 
as mutabilidades organizacionais constantes. Certamente toda esta dinâmica que se apresenta, exige, portanto uma maior efetividade nas atividades operacionais que desdobrem nas buscas da Visão: Garantir disponibilidade e a Missão: Produzir resultados (XAVIER, 2005). De modo a se tornarem mais competitivas, as empresas necessitam que as funções básicas representadas pelos diversos departamentos de sua estrutura apresentem resultados excelentes na busca de status de excelência ou classe mundial (MIRSHAWKA, 1993).

A manutenção, como função estratégica das organizações é responsável direta pela disponibilidade dos ativos, tem importância capital nos resultados da empresa. Esses resultados serão tanto melhores quanto mais eficaz for a gestão da manutenção. Segundo dados estatísticos da Abraman (2003), o Brasil têm custo de manutenção por faturamento bruto de 4,3\% do PIB (Produto Interno Bruto) contra a média mundial de 4,1\%, isso significa para um PIB FGV (Fundação Getúlio Vargas) de US\$ 451 bilhões - representam 19 bilhões em gastos em manutenção. Portanto esta realidade demonstra que as organizações devem procurar as melhorias contínuas na sua gestão da manutenção, buscando-se incessantemente dos conhecimentos inovadoras e aplicação das melhores práticas da manutenção já praticadas nas organizações dos países do primeiro mundo.

O objetivo deste artigo é investigar e apresentar os conhecimentos em gestão da manutenção já publicados em artigos periódicos, dissertações, revistas, livros e relatórios técnicos, resumindo-se as práticas já publicadas, porém de formas fragmentadas em função da divergência nos focos. Constituiu-se em um trabalho de levantamento bibliográfico, pesquisa, observação, análise, classificação e interpretação dos fatos coletados e um estudo de caso - pesquisa sobre tipos de manutenções aplicadas no PIM - Pólo Industrial de Manaus. Esta investigação busca o foco limitado na modalidade da manutenção preditiva, em função da mesma oferecer ferramentas e a que tem o melhor custo/benefício das modalidades conhecidas, e que melhor caracteriza para organizações que buscam a fase inovadora, tendo como o principal objetivo é disponibilizar aos gestores um conjunto de informações técnicas que encoraje na adoção dessa prática, para aquelas organizações que realmente buscam o status de excelência na sua gestão.

O presente estudo utiliza na pesquisa uma abordagem exploratória de caráter quantitativo e qualitativo. Para a classificação da pesquisa quanto à natureza, Vergara (2005), diz que poderá ser de duas formas: qualitativa e quantitativa.

Para Vergara (2005), a pesquisa quantitativa busca quantificar ou determinar o número de respostas mediante uma pergunta, ou um item a ser pesquisado. A presente pesquisa é de natureza quantitativa, porque busca quantificar e determinar o número de respostas mediante uma pergunta e seus itens pesquisados e qualitativos por se tratar de estudo de gestão da manutenção industrial, através da utilização de questões abertas. 
A presente pesquisa caracteriza-se como exploratória; descritiva e explicativa. É exploratória por constituir-se na busca de conhecimentos na área de estudo sobre a gestão da manutenção Industrial, pesquisa, observação, análise, classificação e interpretação dos fatos coletados e, ainda é descritiva porque se pretendeu expor uma das características das metodologias da gestão da manutenção industrial (VERGARA 2005).

No que diz respeito aos meios, Vergara (2005), qualifica a pesquisa como documental, bibliográfica e de campo. Bibliográfica, porque para a fundamentação teórico-metodológica do trabalho realizou-se uma investigação com base nas publicações dos artigos, livros, revistas, jornais e redes eletrônicas dos conceitos aplicados na gestão da manutenção.

\section{Referencial teórico}

Segundo Brito e Pereira (2003), a globalização da economia mundial leva a um constante aumento na competitividade organizacional. Isto coloca em contraste idéias e concepções que aumentam a produtividade, garantindo a qualidade e redução dos custos às organizações. Portanto, a utilização de sistemas de gestão eficientes que possam potencializar a utilização dos recursos nos processos produtivos se traduz como condição sine quan on à performance organizacional.

A manutenção tem procurado novos modos de pensar, técnicos e administrativos, já que as novas exigências de mercado tornaram visíveis as limitações dos atuais sistemas de gestão (MOUBRAY, 1996).

Que a manutenção é uma atividade, meio do processo produtivo que alicerça Segundo os conhecidos fabricantes de classe mundial, cujos produtos competem nos mercados domésticos, bem como nos mercados que se localizam além de suas próprias fronteiras (MIRSHAWKA, 1993).

Para Mirshawka (1993), o termo "classe mundial” significa para um fabricante ter as condições para competir em qualquer lugar do mundo oferecendo produtos com qualidade e com preços atrativos, prazos de entrega e ser reconhecido como um fornecedor confiável.

Segundo Júlio Nascif Xavier (2003) considera bastante adequada a seguinte classificação em função dos tipos de manutenção sendo bastante atualizado em relação à norma ABNT:

Manutenção corretiva é a atuação para correção de falha ou do desempenho menor que o esperado. É oriundo da palavra “corrigir”. Pode ser dividida em duas fases:

Manutenção corretiva não planejada - correção da falha de maneira aleatória, ou seja, é a correção da falha ou desempenho menor que o esperado após a ocorrência do fato. Esse tipo de manutenção implica em altos custos, pois, causa perdas de produção e, em conseqüência, os danos aos equipamentos é maior; 
Manutenção corretiva planejada - é a correção que se faz em função de um acompanhamento preditivo, detectivo ou até mesmo pela decisão gerencial de se operar até ocorrer à falha. "Pelo seu próprio nome planejado", indica que tudo o que é planejado, tende a ficar mais barato, mais seguro e mais rápido.

Manutenção Preventiva - é a atuação realizada para reduzirem falhas ou queda no desempenho, obedecendo a um planejamento baseado em períodos estabelecidos de tempo. De acordo com Xavier (2003) um dos segredos de uma boa preventiva está na determinação dos intervalos de tempo. Como, na dúvida, temos a tendência de sermos mais conservadores, os intervalos normalmente são menores que o necessário, o que implicam paradas e troca de peças desnecessárias;

Manutenção Preditiva - é um conjunto de atividades de acompanhamento das variáveis ou parâmetros que indicam o desempenho dos equipamentos, de modo sistemático, visando a definir a necessidade ou não de intervenção. Segundo Xavier (2003) quando a intervenção, fruto do acompanhamento preditivo, é realizado, fazendo uma Manutenção Corretiva Planejada. Esse tipo de manutenção é conhecido como CBM - CONDITION BASED MAINTENANCE — ou manutenção baseada na condição. Essa manutenção permite que os equipamentos operem por mais tempo e a intervenção ocorre com base em dados e não em suposições;

Manutenção Detectiva - é a atuação efetuada em sistemas de proteção ou comando, buscando detectarem falhas ocultas ou não perceptíveis ao pessoal de operação e manutenção. Um exemplo clássico é o circuito que comanda a entrada de um gerador em um hospital. Se houver falta de energia e o circuito tiver uma falha o gerador não entra. À medida que aumenta a utilização de sistemas automatizados nas operações, o mais importante e mais utilizado será, garantindo a confiabilidade dos sistemas (XAVIER, 2003);

\footnotetext{
Engenharia de Manutenção - "é o conjunto de atividades que permite que a confiabilidade seja aumentada e a disponibilidade garantida". Ou seja, é deixar de ficar consertando convivendo com problemas crônicos —, mas melhorar padrões e sistemáticas, desenvolvendo a manutenibilidade, dar feedback ao projeto e interferir tecnicamente nas compras. Quem só faz a manutenção corretiva continua "apagando incêndio", e alcançando péssimos resultados. Desta forma, a organização que utilizar a manutenção corretiva, mas incorporando a preventiva e a preditiva, rapidamente estará executando a engenharia de manutenção (XAVIER, 2003, p. 5).
}

A norma da ABNT (NBR 5462-1994) as definições de tipos de manutenção são:

Manutenção corretiva é a manutenção efetuada após a ocorrência de uma pane destinada a recolocar um item em condições de executar uma função requerida;

Manutenção preventiva é a manutenção efetuada em intervalos predeterminados, ou de acordo com critérios prescritos, destinada a reduzir a probabilidade de falha ou a degradação do 
funcionamento de um item;

Manutenção preditiva são as manutenções que permitem garantir uma qualidade de serviço desejada, com base na aplicação sistemática de técnicas de análise, utilizando-se de meios de supervisão centralizados ou de amostragem para reduzir a um mínimo a manutenção preventiva e diminuir a manutenção corretiva.

Entre todos os tipos de manutenção nenhuma modalidade substitui outra, porém associadas uma da outra, trarão resultados positivos em termos de performances gerais nas gestões.

A adoção da manutenção preditiva, na concepção de Vaz (1997), leva a supor que seja a solução ideal para as falhas e defeitos nas máquinas e equipamentos, pois ela consiste em interferir na máquina para providenciar manutenção eficaz, no momento adequado. Tal momento é estabelecido mediante estudo e monitoramento cuidadosos dos vários elementos que intervêm no processo de operação, visando detectar a iminência de uma falha.

A utilização desta técnica de manutenção preditiva é a grande quebra de paradigma nos tipos de manutenção. Mirshawka (1991) aponta entre seus maiores benefícios: previsão de falhas com antecedência suficiente para que os equipamentos sejam desativados em segurança, reduzindo os riscos de acidentes e interrupções do sistema produtivo; redução dos prazos e custos de manutenção pelo conhecimento antecipado das falhas a serem reparadas; melhoria nas condições de operação dos equipamentos no sentido de obter menor desgaste, maior rendimento e produtividade.

\subsection{O histórico do desenvolvimento da organização da manutenção}

Segundo Tavares (1998), a história da manutenção acompanha o desenvolvimento técnicoindustrial da humanidade. No fim do século XIX, com a mecanização das indústrias, surgiu a necessidade dos primeiros reparos. Até 1914, a manutenção tinha importância secundária e era executada pelo mesmo efetivo de operação. Com o advento da primeira guerra mundial e a implantação da produção em série, instituída por Ford, as fábricas passaram a estabelecer programas mínimos de produção e, em conseqüência, sentiram necessidade de criar equipes que pudessem efetuar reparos em máquinas operatrizes no menor tempo possível. Assim surgiu um órgão subordinado à operação, cujo objetivo básico era de execução da manutenção, hoje conhecida como manutenção corretiva. Esta situação se manteve até a década de 30, quando, em função da segunda guerra mundial e da necessidade de aumento de rapidez de produção, a alta administração industrial passou a se preocupar, não só em corrigirem falhas, mas evitar que elas ocorressem, e o pessoal técnico de manutenção passou a desenvolver o processo de prevenção de avarias que, 
juntamente com a correção, completavam o quadro geral de manutenção, formando uma estrutura tão importante quanto à de operação.

Por volta de 1950, com o desenvolvimento da indústria para atender aos esforços pós-guerra, a evolução da aviação comercial e da indústria eletrônica, os gerentes de manutenção observaram que, em muitos casos, o tempo gasto para diagnosticar as falhas era maior do que o despendido na execução do reparo, e selecionaram equipes de especialistas para compor um órgão de assessoramento que se chamou Engenharia de Manutenção e recebeu os encargos de planejar e controlar a manutenção preventiva e analisar causas e efeitos das avarias e os organogramas se subdividiram.

A partir de 1966, com a difusão dos computadores e a sofisticação dos instrumentos de proteção e medição, a engenharia de manutenção passou a desenvolver critérios de predição ou previsão de falhas, visando à otimização da atuação das equipes de execução de manutenção. Esses critérios, conhecidos como manutenções preditiva ou previsiva, foram associados aos métodos de planejamento e controle de manutenção automatizado, reduzindo os encargos burocráticos dos executantes de manutenção. Estas atividades acarretaram o desmembramento da engenharia de manutenção que passou a ter duas equipes: a de estudos de ocorrências crônicas e a de PCM Planejamento e Controle de Manutenção, esta última com a finalidade de desenvolver, programar e analisar os resultados dos sistemas automatizados de manutenção (TAVARES, 1998).

\footnotetext{
Ainda Tavares (1998, p.13), “a partir de 1980 com o desenvolvimento dos microcomputadores, a custos reduzidos e linguagens simples, os órgãos de manutenção passaram a desenvolver e processar seus próprios programas, eliminando os inconvenientes da dependência de disponibilidade humana e de equipamentos para o atendimento as suas prioridades de processamento das informações pelo computador central, além de dificuldade de comunicação na transmissão de suas necessidades para o analista de sistemas, nem sempre familiarizada com a área de manutenção. Esta situação favoreceu o PCM que pôde melhor desempenhar suas funções de assessoramento aos gerentes, não só de manutenção, mas também, de operação e de produção. No final de século passado, com as exigências de aumento da qualidade dos produtos e serviços pelos consumidores, à manutenção passou a ser um elemento importante no desempenho dos equipamentos em grau equivalente ao que já vinha sendo praticado na operação. Em conseqüência o PCM (assim como a engenharia de manutenção) passou a desempenhar importantes funções estratégicas dentro da área de produção através do manejo das informações e da análise de resultados para auxiliar aos gerentes (produção, operação e manutenção) em suas missões de tomada de decisão, sendo então recomendado que tanto a engenharia de manutenção quanto o PCM passem a ocupar posição de "staff" a toda área de produção (nas empresas de processo ou serviço)".
}

\subsection{Tendências mundiais de tipo de manutenção}

Analisando-se as empresas líderes, ou de sucesso, percebe-se que essas organizações adotam, cada vez mais, técnicas preditivas e a prática da engenharia de manutenção. A manutenção, assim, é considerada estratégica para as organizações, pois ela garante a disponibilidade dos 
equipamentos e instalações com confiabilidade, segurança e dentro de custos adequados (XAVIER, 2005). De acordo com a tendência mundial, entender o tipo de manutenção adequada para cada organização é fator de sucesso, garantia de otimização nos processos e, por conseguinte, à atividade auferir lucros, ou seja, não apenas garantir a sobrevivência das organizações, mas possibilitar-lhes crescimento e expansão.

No Brasil ainda se trabalha com muita manutenção corretiva não planejada e com manutenção preventiva em excesso. Entre 1992 e 2003, o nível de atuação, segundo o Documento Nacional da Abraman - Tabela 1 ficou em média, nos seguintes valores percentuais:

Tabela 1 - Nível de atuação no Brasil

\begin{tabular}{l|l}
\hline Tipo de Manutenção & \% \\
\hline Manutenção Corretiva & 28 \\
\hline Manutenção Preventiva & 36 \\
\hline Manutenção Preditiva & 19 \\
\hline Engenharia da Manutenção & 17 \\
\hline Fonte: Abraman (2003) &
\end{tabular}

Tem que promover uma mudança de modo que o nível de atuação, através da aplicação de manutenção preditivas, seja aumentado mais rapidamente. É necessário reduzir fortemente a manutenção preventiva e aumentar a participação da manutenção preditiva como forma de obtermos melhores resultados para empresas do nosso país. A manutenção preditiva é a $1^{\circ}$ quebra de paradigma na manutenção e através dela estaremos no caminho para a excelência.

\section{Caracterização da manutenção preditiva}

Num artigo do autor Nascif (2002), define que a manutenção preditiva é a atuação realizada com base na modificação de parâmetro de condição ou desempenho do equipamento, cujo acompanhamento obedece a uma sistemática. A manutenção preditiva pode ser comparada a uma inspeção sistemática para o acompanhamento das condições dos equipamentos.

Quando é necessária a intervenção da manutenção no equipamento, estamos realizando uma manutenção corretiva planejada.

É conhecida também como manutenção sob condição ou manutenção com base no estado do equipamento (Condition Based Maintenance).

O termo associado à manutenção preditiva é o de "predizer". Esse é o grande objetivo da manutenção preditiva: predizer (ou prever) as falhas nos equipamentos ou sistemas através de acompanhamento dos diversos parâmetros, permitindo a operação contínua pelo maior tempo possível. Ou seja, a manutenção preditiva privilegia a "disponibilidade" á medida que não promove intervenções nos equipamentos em operação. 
Além disso, a intervenção só é decidida quando os parâmetros acompanhados indicam sua real necessidade. Quando o grau de degradação se aproxima ou atinge o limite previamente estabelecido, é tomada a decisão de intervenção. Isto permite uma preparação prévia do serviço, além de outras decisões alternativas relacionadas com a produção.

\subsection{Estruturação da manutenção preditiva}

A estruturação da manutenção preditiva, desenvolvimento das tecnologias de diagnósticos é basicamente definida em 8 etapas:

- Pesquisa das necessidades (custos);

- Seleção de componentes / equipamentos prioritários em classes $\mathrm{ABC}$;

- Coleta de informações externas à empresa para obtenção de tecnologias;

- Estrutura para execução e fluxo do sistema de manutenção preditiva;

- Treinamento dos responsáveis;

- Testes;

- Seleção de software e hardware;

- Desenvolvimento gradual do sistema na empresa:

a) Seleção e ampliação dos equipamentos e partes que são objetos da manutenção preditivas;

b) Desenvolvimento de equipamentos e tecnologias de diagnóstico.

A manutenção preditivas é a atuação realizada com base em modificação de parâmetro de CONDIÇÃO ou DESEMPENHO, cujo acompanhamento obedece a uma sistemática.

\subsubsection{Acompanhamento preditivo}

A avaliação do estado do equipamento se dá através de medição, acompanhamento ou monitoração de parâmetros. Esse acompanhamento pode se feito de três formas:

- Acompanhamento ou monitoração subjetiva;

- Acompanhamento ou monitoração objetiva;

- Monitoração contínua.

Monitoração subjetiva - é aquela exercida pelo pessoal de manutenção utilizando os sentidos, ou seja, tato, olfato, audição e visão. Quando um mecânico coloca a palma da mão sobre uma caixa de mancal, pode perceber a temperatura e a vibração. Evidentemente quanto mais experiente, mais confiáveis serão os diagnósticos; no entanto esta monitoração não deve ser adotada como base para decisão por ser extremamente subjetiva. 
Monitoração objetiva - é o acompanhamento feito através de equipamentos ou instrumentos específicos. É objetiva, pois:

- Fornece um valor de medição do parâmetro que está sendo acompanhado;

- O valor medido independe do operador do instrumento, desde que utilizado o mesmo procedimento.

Monitoração contínua - é o acompanhamento "on line" das variáveis dos equipamentos através dos sensores implantados neles.

\subsubsection{Principais técnicas de manutenção preditiva}

Em termos práticos, uma técnica de manutenção preditiva deve atender aos seguintes requisitos:

- Permitir a coleta de dados com o equipamento em funcionamento, ou com o mínimo de interferência possível no processo de produção;

- Permitir a coleta dos dados que possibilitem a análise de tendência.

Somente para efeito didático, podem classificar as técnicas Preditivas nas categorias indicadas no Quadro 1.

Quadro 1 - As técnicas preditivas nas categorias

\begin{tabular}{|c|c|}
\hline $\begin{array}{l}\text { Radiações ionizantes } \\
\text { Raios X Gama grafia }\end{array}$ & $\begin{array}{l}\text { Energia acústica } \\
\text { Ultra-som, emissão acústica }\end{array}$ \\
\hline $\begin{array}{l}\text { Energia eletromagnética } \\
\text { Partículas magnéticas } \\
\text { Correntes parasíticas }\end{array}$ & $\begin{array}{l}\text { Fenômenos de viscosidade } \\
\text { (Líquidos penetrantes) }\end{array}$ \\
\hline $\begin{array}{l}\text { Inspeção visual } \\
\text { Endoscopia ou boros copia } \\
\text { Detecção de vazamentos }\end{array}$ & $\begin{array}{l}\text { Análise de vibrações } \\
\text { Nível global, espectro de vibrações } \\
\text { Pulso de choque }\end{array}$ \\
\hline $\begin{array}{l}\text { Análise de Óleos lubrificantes ou isolantes } \\
\text { Viscosidade, número de neutralização acidez } \\
\text { ou basicidade, teor de água insolúvel, } \\
\text { contagem de partículas metais por } \\
\text { espectrometria por infravermelha } \\
\text { cromatografia gasosa, tensão interfacial, } \\
\text { rigidez dielétrica, ponto de fulgor. }\end{array}$ & $\begin{array}{l}\text { Análise de temperatura - termometria } \\
\text { Termometria convencional } \\
\text { Indicadores de temperatura } \\
\text { Pirometria de radiação } \\
\text { Termografia }\end{array}$ \\
\hline $\begin{array}{l}\text { Ferrografia } \\
\text { Ferrografia quantitativa } \\
\text { Ferrografia analítica }\end{array}$ & $\begin{array}{l}\text { Verificações de geometria } \\
\text { Metrologia convencional } \\
\text { Alinhamento de máquinas rotativas }\end{array}$ \\
\hline $\begin{array}{l}\text { Ensaios elétricos } \\
\text { Corrente, tensão, isolação perdas dielétricas, } \\
\text { rigidez dielétrica, espectro de corrente ou } \\
\text { tensão. }\end{array}$ & $\begin{array}{l}\text { Forças } \\
\text { Célula de carga teste de pressão, teste hidrostático, } \\
\text { teste de vácuo, detecção de trincas. }\end{array}$ \\
\hline
\end{tabular}

Fonte: Adaptado de Kardec (2002) 
Algumas técnicas de Ensaios Não Destrutivos (END), listadas na tabela, só podem ser aplicados com o equipamento fora de operação, o que invalidaria a condição de que as técnicas preditivas são aplicáveis com o equipamento em funcionamento. Para melhor visualização considerar que as técnicas listadas nos quadros em negritos são aplicáveis com o equipamento em operação enquanto as contidas nos quadros normais (não negritos) dependem (em geral) da retirada do equipamento de operação para sua realização. Neste artigo serão abordadas apenas as técnicas preditivas que podem ser aplicadas com os equipamentos em operação.

\subsubsection{Análise de vibrações}

O acompanhamento e a análise de vibração tornaram-se um dos mais importantes métodos de predição na indústria tendo a sua maior aplicação em equipamentos rotativos (bombas, turbinas, redutores, ventiladores, compressores). O estágio atual de desenvolvimento dos instrumentos, sistemas de monitoração e softwares especialistas é muito avançado, o que vem permitindo, por exemplo, que outras variáveis, além da vibração, sejam acompanhadas simultaneamente pelos mesmos instrumentos.

\subsubsection{Temperatura}

A temperatura é um dos parâmetros de mais fácil compreensão e o acompanhamento de sua variação permite constatar alteração na condição dos equipamentos, componentes e do próprio processo produtivo. A seguir estão listados alguns exemplos clássicos, onde a monitoração da temperatura é primordial:

- Temperatura de mancais de maquinas rotativas;

- Temperatura da superfície de equipamentos estacionários;

- Temperatura de barramentos e ligações (conexões) elétricas.

A medição de temperatura pode ser feita por uma série de instrumentos, alguns dos quais estão listados a seguir:

- Termômetro de contato;

- Termometria convencional;

- Pirômetro de radiação ou pirômetro ótico;

- Termógrafos ou termovisores.

Uma das técnicas preditivas que proporciona maior retorno e evita a ocorrência de acidentes ou paradas de produção é a termografia em instalações elétricas. O mau contato, a partir do qual se desencadeia a falha, pode ser detectado e corrigido pela utilização de radiômetros ou de termovisores. 
Por sua relevância para a manutenção, tanto em indústrias como em instalações prediais, é altamente recomendável a existência de um programa de acompanhamento das instalações elétricas.

A Termografia é uma das técnicas preditivas que mais tem se desenvolvido nos últimos 30 anos. Atualmente os termovisores estão cada vez menores e mais precisos. Oferecendo recursos importantes para o acompanhamento e controle de tendência.

Algumas das principais aplicações da termografia em instalações industriais são:

- Área elétrica onde existe necessidade de acompanhamento de componentes defeituoso ou mau contato;

- Usinas siderúrgicas - verificação do revestimento de altos fornos, dutos de gás, regeneradores e carros torpedos;

- Fabrica de cimento - fornos rotativos para pesquisa de queda de refratários;

- Área de petróleo e petroquímico - vazamentos em válvulas de segurança, problemas com refratários em fornos, caldeiras e unidades de craqueamento catalítico.

\subsubsection{Detecção de vazamentos}

Os vazamentos se constituem um dos maiores problemas nas indústrias, instalações prediais, transportes, enfim qualquer área da atividade humana. A detecção e correção de vazamentos são importantes tanto no aspecto de segurança como nos aspectos de custos, conservação de energia e preservação do meio ambiente. Existem vários métodos para se fazer a detecção de vazamentos. Os mais conhecidos são os detectores de gás, os instrumentos eletrônicos que provocam alarme ou acendem lâmpada na presença de gás e os instrumentos ultra-sônicos para detectar ruídos em alta freqüência.

\subsubsection{Análise de óleo}

De acordo com o Baroni (2002), existem duas formas de encararmos as informações obtidas a partir de uma análise de óleo:

Condições do lubrificante - determinação das propriedades físico-químicas do lubrificante para garantir uma boa lubrificação;

Condições da máquina - análise de substâncias estranhas ao lubrificante (gases ou partículas em suspensão no lubrificante).

Para avalias das condições do lubrificante estão disponíveis diversos testes de viscosidade:

- Índice de Neutralização - Acidez (TAN) e Basicidade (TBN);

- Teor da água;

- Insolúveis; 
- Espectrometria (presença de metais);

- Rigidez Dielétrica;

- Ponto de Fulgor.

\subsubsection{Ferrografia}

Ferrografia consiste na determinação da severidade, modos e tipos de desgaste em máquinas por meio da identificação da morfologia, acabamento superficial, coloração, natureza e tamanho das partículas encontradas em amostras de óleos ou graxas lubrificantes de qualquer viscosidade, consistência e opacidade (BARONI, 2002). Atualmente a ferrografia é capaz de identificar metais não-ferrosos (bronze, alumínio, cromo etc.), contaminantes sólidos de todo tipo (areia, fibras orgânicas e inorgânicas, sais e etc.) e ainda produtos de degradação do lubrificante (borras, gel, lacas, vernizes e etc.).

\subsection{Custos por tipos de manutenção}

A primeira e principal comparação de custos deve ser feita entre os vários tipos de manutenção corretiva não planejada é, pelo menos, o dobro do custo de manutenção preditiva conforme Tabela 2. Outro aspecto importante, relacionado aos custos, está no modo de executar o programa de manutenção preditivas: se com recursos próprios ou contratando os serviços de firmas especializadas. De modo a permitir uma análise mais detalhada, incluímos os valores de mercado para equipamentos, softwares e prestação de serviços.

Tabela 2 - Custo Médio de Manutenção

\begin{tabular}{l|c|c}
\hline TIPO DE MANUTENÇÃO & CUSTO US\$ /HP/ANO & RELAÇÃO \\
\hline Corretiva não Planejada & $17,00 \sim 18,00$ & 2,0 \\
\hline Preventiva & $11,00 \sim 13,00$ & 1,5 \\
\hline Preditiva & $7,00 \sim 9,00$ & 1,0 \\
\hline
\end{tabular}

Fonte: Artigo - Gestão para a Manutenção Classe Mundial (Xavier, 2005)

\section{Análise e discussão dos resultados da pesquisa}

A manutenção preditiva embora tenha um menor custo operacional, porém requer pessoal treinado para executá-la e 100\% dedicados a esta atividade (MIRSHAWKA, 1993). E para o mesmo autor, é óbvio que o nível de sofisticação de manutenção preditiva está associado à importância econômica dos equipamentos que buscamos disponibilidade maior:

A manutenção preditiva não é uma forma cara de manutenção (o mais barato naturalmente seria não fazer a manutenção, porém, isto é uma história, ou melhor, outro assunto...) e custa em média menos do que a metade do custo da manutenção corretiva, após a quebra; 
Porém, para se implantar a manutenção preditiva deve-se obter um intenso comprometimento gerencial e, além disto, precisa ser bem organizada para ser eficiente quanto ao assunto e a produtividade;

A manutenção preditiva deve ser feita por especialistas, os quais naturalmente deverão ser bem treinados e equipados, seguindo rotas e verificações pré-determinadas e que não façam nada além de manutenção preditiva!;

No Brasil, ainda são muitos os departamentos de manutenção nos qual a manutenção preditiva é algo totalmente estranho. Eles podem ter ouvido falar sobre isso, porém não sabem realmente o que é ou como pode ser aplicado no seu particular caso;

Recomenda-se que todo equipamento crítico, ou seja, aquele cuja falha interromperia ou pararia a produção, aumentaria os custos de energia ou ainda traria grandes problemas para o controle de segurança, deve ser "coberto" por um sistema de manutenção preditiva.

As ações requeridas são as seguintes:

- Identificar os equipamentos críticos que justificam investimentos para esse tipo de manutenção;

- Examinar e escolher as técnicas preditivas recomendadas para os diferentes tipos de equipamentos;

- Implementar o programa de manutenção preditiva, treinando a respectiva equipe para essa tarefa;

- Criar uma base de dados para decisões futuras.

\subsection{Estudo de caso}

De acordo com as informações obtidas na pesquisa - questionário, foi possível identificar, de acordo com a Tabela 3 e 4, que as atividades de manutenção desenvolvidas pelas empresas do PIM - Pólo Industrial de Manaus são: predominantemente 65\% atuam nas manutenções corretivas e preventivas, índice próximo da tendência nacional Tabela 1 com 64\% $(28+36)$, e 35\% praticam a manutenção preditiva contra $19 \%$ de nível nacional, porém a pesquisa mostrou uma surpresa que nenhuma das empresas pesquisadas não pratica a engenharia da manutenção, em contraste significativo com o nível nacional de $17 \%$. Somente uma empresa manifestou que tem plano no futuro pela implementação da engenharia da manutenção. 
Tabela 3 - Tipo de Manutenção adotado no PIM - Pólo Industrial de Manaus

\begin{tabular}{|c|c|c|}
\hline Tipo de Manutenção aplicada & freq. & f.relativa (\%) \\
\hline Manutenção corretiva não programada + preventiva & 13 & 65,0 \\
\hline Manutenção corretiva não programada + programada + preventiva + preditiva & 7 & 35,0 \\
\hline Manutenção corretiva não programada + programada + preventiva + preditiva + detectiva & 0 & 0,0 \\
\hline Manutenção corretiva não programada + programada + preventiva + preditiva + detectiva + eng.da manutenção & 0 & 0,0 \\
\hline Outros & 0 & 0,0 \\
\hline$\sum$ & 20 & 100 \\
\hline
\end{tabular}

Fonte: Autor

Tabela 4 - Plano para busca de Excelência na Gestão da Manutenção nas empresas do PIM

\begin{tabular}{lcc}
\hline Existe plano para busca de excelência na gestão da manutenção na sua empresa? & freq. & f. relativa (\%) \\
\hline Sim & 5 & 25,0 \\
Não & 75,0 & 15 \\
$\sum$ & 100 & 20 \\
\hline
\end{tabular}

Fonte: Autor

\section{Conclusão}

De acordo com os dados obtidos por meio da pesquisa, foi possível chegarem aos seguintes conclusões referentes às dimensões da gestão da manutenção, foco de análise desse estudo. Estimular as organizações do PIM na busca de melhoria do resultado operacional a partir de uma maior eficiência de todo o sistema de produção assim como conservar o parque fabril a um custo compatível, foi o que estimulou o autor em desenhar uma proposta de implementação de um programa de gestão da manutenção em busca da visibilidade a excelência ou classe mundial ou ainda no mínimo sair da atual fase "controladora" para "inovadora".

A pesquisa mostrou que existem ainda várias empresas do PIM - Pólo Industrial de Manaus, as atividades de manutenção têm como base as do tipo corretiva e preventiva, conforme os dados mostrado nas Tabelas 3 e 4 da pesquisa, sendo $25 \%$ das empresas manifestaram que têm planos e estudos para busca de status de excelência na gestão da manutenção industrial.

$\mathrm{O}$ artigo buscou apresentar as principais características de um sistema de manutenção preditiva no ambiente de produção focada nas organizações industriais do PIM. A pesquisa procurou expor as principais definições e passos de implementação em termos do que realmente é importante quando se trata da gestão da manutenção das máquinas, equipamentos de produção e das instalações, suportada pela incorporação da manutenção preditiva. . A idéia do implemento desta ferramenta não é substituição de outras ferramentas clássicas (manutenção corretiva e preventiva). A manutenção preditiva tem como objetivo principal em reduzir os custos de manutenção corretiva e preventiva.

Dessa forma, este trabalho suporta a hipótese de que pela aplicação da manutenção preditiva de maneira eficiente os setores de produção, complementados pelas manutenções detectiva e da engenharia de manutenção, as empresas podem alcançar seus objetivos estratégicos e, estar assim, melhor preparadas para lidar com os constantes desafios de um mercado competitivo e servirá como alicerce para busca da excelência. 
Por fim, o autor enfatiza que a adoção de um modelo de sistema de manutenção que utilize a manutenção preditiva aponta para uma gestão mais eficaz das máquinas, equipamentos do setor produtivo e das instalações em gerais. Para que isto possa ser feito, é necessário que além de identificar todas as restrições dos sistemas produtivos e disponibilizar os recursos materiais necessários para a transformação, os gestores e os mantenedores sejam tratados como atores importantes desse processo. Pois assim, a empresa pode buscar um melhor resultado econômicofinanceiro, proporcionando pacotes de valor aos stakeholders.

\begin{abstract}
The present article looks for a broaching about the development proposal of the industrial maintenance in the excellence or world class search, recommended to the organizations that are already in the controlling stage, and that intend the facing of the new challenging phase innovation. The objective of this article is to investigate and to present the already published knowledge in maintenance administration in periodical articles, dissertations, magazines, books and technical reports, summarizing to the already published experiences. It was constituted in a bibliographical, research, observation, analysis, classification and interpretation of the collected facts and a case study - research about the types of applied maintenance in the PIM - "Pólo Industrial de Manaus". In intention of describing an integration of information, criterion and experience case, unifying in the possible covering way of the technical information and in order to create a bigger consistency in the maintenance management practice. The hypothesis is supported that, by the application of the condition based maintenance in an efficient way in the production area, complemented by the detection maintenance and maintenance engineering, the companies will go towards to reach their strategic goals, and be, this way, better prepared to deal with the constant challenges of a competitive market and important advance in the excellence search.
\end{abstract}

Key-words: Condition Based Maintenance, Detection Maintenance, Engineering of the Maintenance and Administration of the Maintenance.

\title{
6. Referências
}

ASSOCIAÇÃO BRASILEIRA DE NORMAS TÉCNICAS, NBR 5462: Confiabilidade e mantenabilidade. Rio de Janeiro: ABNT, 1994.

BRITTO, R. de; PEREIRA, M. A. (2003) - Manutenção autônoma: estudo de caso em empresa de porte médio do setor de bebidas. In: VII SEMEAD, Seminário de Estudos de Administração da USP - Universidade de São Paulo.

CONGRESSO BRASILEIRO DE MANUTENÇÃO, 18 , 2003, Porto Alegre. A situação da manutenção no Brasil: Abraman - Associação Brasileira de Manutenção, 2003.

KARDEC, Alan; NASCIF, Julio; BARONI, Tarcísio. Gestão Estratégica e Técnicas Preditivas. Editora Quality Mark, Rio de Janeiro, 2002 . Coleção Manutenção, Abraman.

KARDEC, Alan; NASCIF, Julio. Manutenção Função Estratégica, 2a edição, $1^{\text {a }}$ Reimpressão 2004. Editora Quality Mark, Rio de Janeiro, Coleção Manutenção, Abraman.

MIRSHAWKA, V.; Manutenção Preditiva: Caminho para Zero Defeitos, 1 ed. São Paulo: Makron Books, McGrawHill, 1991. 
MIRSHAWKA, V.; OLMEDO, N.L. Manutenção - Combate aos Custos da Não-Eficácia:

A Vez do Brasil . São Paulo: Makron Books do Brasil Editora Ltda., 1993.

MOUBRAY, John. Introdução à Manutenção Centrada na Confiabilidade. São Paulo: Aladon, 1996.

XAVIER, Julio Nascif. Manutenção Preditiva Caminho para a excelência. Disponível em:

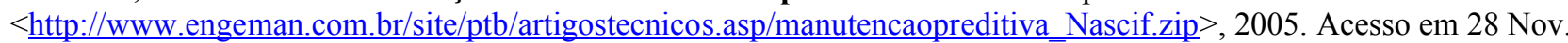
2007.

XAVIER, Julio Nascif. Manutenção: Tipos e Tendências. Disponível em:

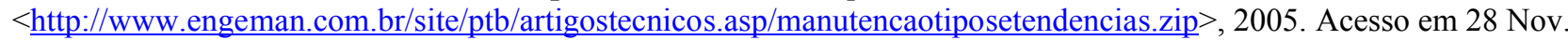
2007.

TAVARES, Lourival. Administração Moderna de Manutenção. Novo Pólo Editora - New York, 1998.

VAZ, José Carlos. Gestão da Manutenção Preditiva: Gestão de

Operações. Fundação Vanzolini. Ed. Edgard Blücher, 1997.

VERGARA, Sylvia Constant. Projetos e relatórios de pesquisa científica em

administração. $6^{\text {a }}$ ed. São Paulo: Ed. Atlas, 2005.

\section{Dados dos autores:}

Nome completo: Mario Otani

Filiação institucional: Universidade Federal do Amazonas - UFAM

Departamento: FT - Faculdade de Tecnologia

Função ou cargo ocupado: Mestrando em Engenharia de Produção

Endereço completo para correspondência (bairro, cidade, estado, país e CEP): Rua 5 casa 43, Conj.

Villar Câmara, Bairro Aleixo, Manaus - Amazonas - Brasil, CEP 69083-390

Telefones para contato: (92) 3248-8347 ou (92) 8801-3150

e-mail:_mariootani@gmail.com

Nome completo: Prof ${ }^{\circ}$. PhD Waltair Vieira Machado

Filiação institucional: Universidade Federal do Amazonas - UFAM

Departamento: FT - Faculdade de Tecnologia

Função ou cargo ocupado: Diretor da Faculdade de Tecnologia

Endereço completo para correspondência (bairro, cidade, estado, país e CEP): Av. General Rodrigo

Otávio Jordão Ramos, 3000, Bairro Aleixo, Manaus - Amazonas - Brasil, CEP 69077-000

Telefones para contato: (92) 3647-4433 / 3647-4432

e-mail:waltairmachado@ufam.edu.br 